\title{
Distress Assessment and Response Tool
}

National Cancer Institute

\section{Source}

National Cancer Institute. Distress Assessment and Response Tool. NCI Thesaurus.

Code C141520.

A short, self-assessment to measure an individual's physical symptoms, emotional burden and practical concerns that could interfere with their ability to eng age in cancer treatment. 